\title{
Modeling and Dynamic Behavior Simulation Study on Offshore Container Crane Based on ADAMS
}

\author{
Haiyan Qiang ${ }^{1,2, a}$, Wanli Li ${ }^{1, b}$, Yougang Sun ${ }^{1,2, c_{*}}$ and Chen Chen ${ }^{2, d}$ \\ ${ }^{1}$ School of Mechanical Engineering, Tongji University, Shanghai 201804, China, ${ }^{2}$ Full address of \\ second author, including country \\ ${ }^{2}$ College of Logistics Engineering, Shanghai Maritime University, Shanghai 201306, China

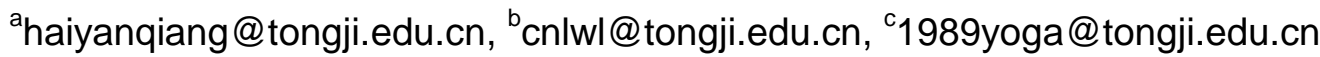 \\ *The corresponding author
}

Keywords: Offshore container crane; Nonlinear dynamic; ADAMS; Sea wave

\begin{abstract}
In order to study the nonlinear dynamic response of the offshore container crane under sea wave, the virtual prototype model of the offshore container crane is established. Firstly, the 3D geometry model of offshore container crane is built in SOLIDWORKS. Then the model is introduced to ADAMS, and defines the dynamics properties to achieve the complete dynamic model. Finally, according to the different sea conditions, the simulations of the offshore container crane is included to show that the research method proposed in this paper is feasible, which can provide useful reference for the design of the offshore container crane.
\end{abstract}

\section{Introduction}

The offshore container crane is used to load/unload containers between a huge container ship (called the "mother ship") and a smaller ship (called the "mobile harbor"), on which the crane is installed. The purpose of the mobile harbor is to load/unload containers in the open sea and transport them to shallower water where they can be offloaded at existing conventional ports, thereby obviating the inconvenience of the traditional crane system [1-4].

Due to the harsh working environment, the offshore container crane experiences more problems than conventional cranes that are fixed into the ground[5-7] .One of the serious problems is the swing of the load caused by improper control of the trolley and influence of external disturbances such as the wave and wind[8-10]. This is a serious problem, because it could cause extensive damage to surrounding devices and systems. Therefore, the dynamic analysis of offshore container crane under sea wave is a challenge to solve.

The virtual prototype model of the offshore container crane is established. The rest of this paper is organized as follows: first, the 3D geometry model of offshore container crane is built in SOLIDWORKS. Then the model is introduced to ADAMS, and defines the dynamics properties to achieve the complete dynamic model. Finally, according to the different sea conditions, the simulation of the offshore container crane is included to show the dynamic response.

\section{The Establishment of the Three-Dimensional Solid Model}

The base of the virtual prototype system development is the geometry solid modeling. ADAMS/View software itself provides a graphical tool for 3D modeling while the traditional computer assisted design software like CAD, UG; SolidWorks are quite weak in modeling function and quite inconvenient for dealing with complex mechanical systems. Considering that the offshore container crane is a kind of big assembly with multi-complex parts, meanwhile, in order to obtain the similarity and fidelity between the prototype and the entity, SolidWorks, which is technical solid modeling software, is utilized to build 3D models and assemble to the system mechanism of the offshore container cranes. 
The floating platform, crane and trolley of the offshore container crane, which is assembled according to the engineering practice, are established in Solid works and the assembly has been shown in Fig. 1.

\section{The Establishment of Dynamic Model in ADAMS Environment}

The Parasolid standard is used as the kernel of the entity modeling in Solidworks and ADAMS, so the model of Solidworks can be exported to the Parasolid file (whose file name is $\mathrm{x} \_t$ or Xmt_txt). And then the model is imported through the import ADAMS option. The Solidworks assembly model of floating container crane is imported to the ADAMS, in order to avoid the trouble of assembly in ADAMS.

As shown in Fig. 2, it is the floating container crane system model is imported in ADAMS software.

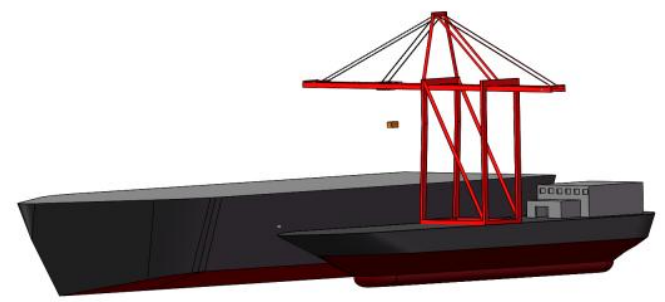

Figure 1. the 3D model of OCC

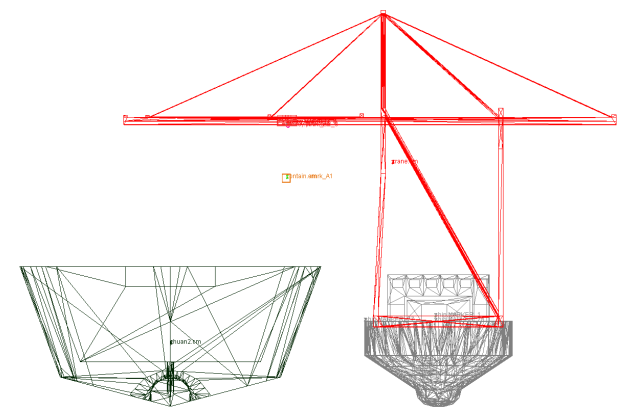

Figure 2. the dynamic model based on ADAMS

After importing the model into the ADAMS software, each component is not an independent whole. In order to achieve the connection between the components, the relative motion between the two individual components can be defined by creating a motion pair. ADAMS/View provides a variety of constraints for the parts connection, which are most commonly used to have 12 .

The floating container crane system model has 7 main components in the ADAMS, respectively, ground, door frame structure, girder, trolley, hoisting wire rope, container crane, floating platform and large container ship.

The constraints are added between components to form a whole. The following constraints on the model are carried out:

Table 1 Adding constraints

\begin{tabular}{|c|c|c|}
\hline Body parts & The name of motion Joint & number \\
\hline The door frame and the crane girder & Fixed Joint & 1 \\
\hline $\begin{array}{c}\text { The structure of the door frame and } \\
\text { barges }\end{array}$ & Fixed Joint & 1 \\
\hline The trolley and rail girder & Translational Joint & 1 \\
\hline
\end{tabular}

The adding of the wire rope can be quickly completed with the newly developed ADAMS rope module

ADAMS rope module features:

1) The characteristics of wire rope and puller can be simulated conveniently.

2) The Rapid modeling and simulation evaluation of rope pulley system is realized

3) The calculation of tension and vibration of steel wire rope

4) Analyze the influence of the slip of rope on the carrying capacity of the system.

Fig. 3 shows the rope module for floating container crane. 


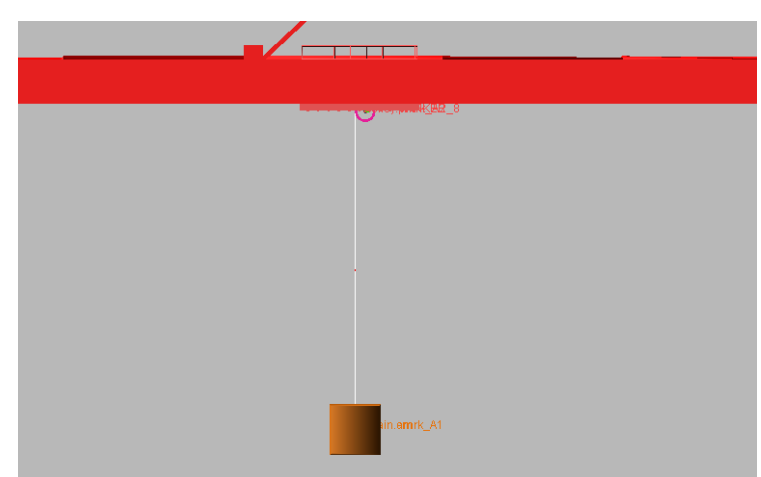

Figure 3. The dynamic model of wire rope

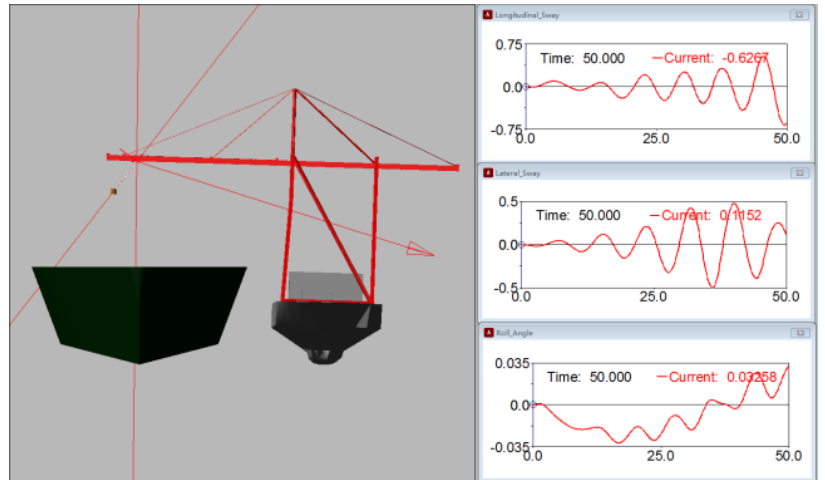

Figure 4. The simulation realization of OCC

As shown in Fig. 4, the trolley is applied the drive to reach the specified speed and move to the specified position, the simulation results of barges is incentive by real wave excitation. Simulation time, weight of lifting weight, fixed length.

The measured load swing angles, surface and corner roll angle of pontoon.

\section{Simulation Results and Analysis}

In order to compare the dynamic response of the system under the action of different sea conditions, the ship heave, roll and yaw drive three directions is simplified as the rules of harmonic motivation, simulated by polynomial, These motivation are superimposed on the movement of the ship 3 degrees of freedom, and applied in the floating container crane at the center of the hull, the sea parameters are shown in table 2.

Table 2 the parameters of Sea state

\begin{tabular}{ccccc}
\hline $\begin{array}{c}\text { Sea } \\
\text { conditions(level) }\end{array}$ & $\begin{array}{c}\text { wave height } \\
(\mathrm{m})\end{array}$ & $\begin{array}{c}\text { Amplitude } \\
(\mathrm{m})\end{array}$ & $\begin{array}{c}\text { Frequency } \\
(\mathrm{rad} / \mathrm{s})\end{array}$ & Times $(\mathrm{s})$ \\
\hline 3 & $0.5 \sim 1.25$ & 0.4 & 1.257 & 5.0 \\
4 & $1.25 \sim 2.5$ & 0.94 & 0.924 & 6.8 \\
5 & $2.5 \sim 4$ & 1.63 & 0.714 & 8.8 \\
\hline
\end{tabular}

The model simulation under the condition of the system respectively were three, 4 and 5 level of the sea environment, the comparison of the simulation results as follows:

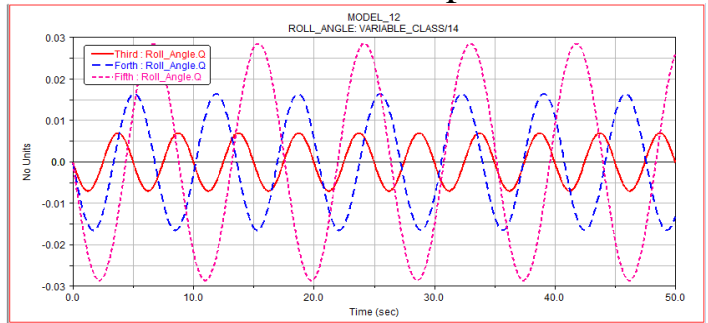

(a) the rolling angle of ship (rad)

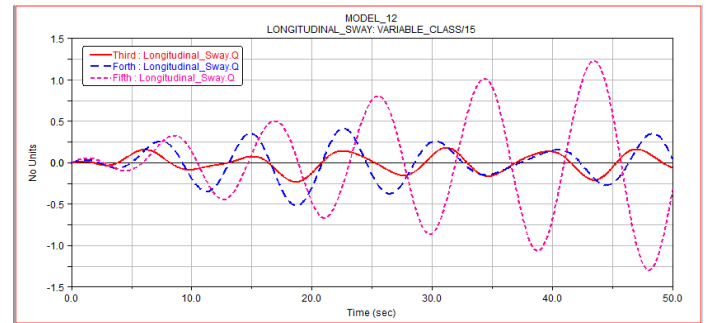

(b) the sway angle of payload (rad)

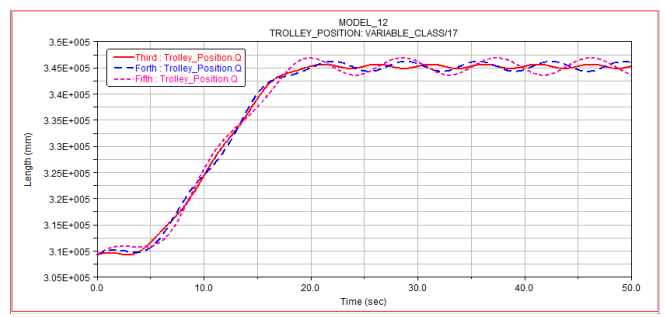

(c) the trolley position under 3, 4 and 5 sea conditions $(\mathrm{mm})$

Figure 5. the simulation results under all levels sea condition 
The length of the steel wire rope is $15 \mathrm{~m}$, the weight of lifting weight is $20 \mathrm{t}$, and the natural frequency of the lifting system is:

$$
\omega_{n}=\sqrt{g / L} \approx 0.808 \mathrm{rad} / \mathrm{s}
$$

In order to compare the effects of different wave frequency excitation on the motion of the floating platform and the floating container crane, the simulation is carried out under the wave excitation frequency of (1), respectively.

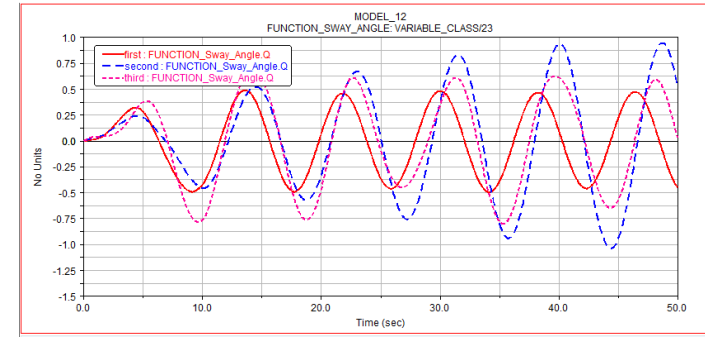

(a) the sway angle of payload

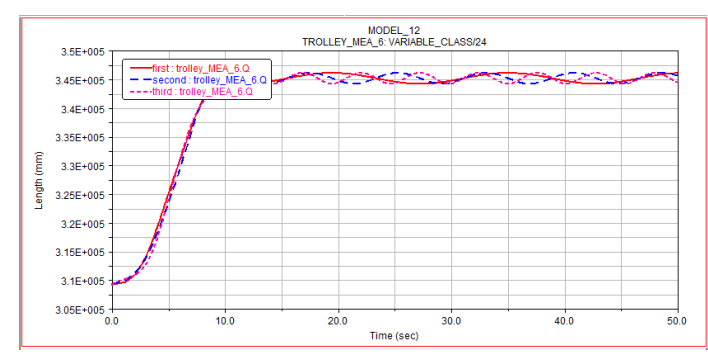

(b) the trolley position under frequency of wave

Figure 6. the simulation results under different frequency of wave

The influence of the length of steel wire rope on the floating container crane system is analyzed. On the basis of the three level simulation environment, rope length is changed by the function of editing model. Simulation results for the $15 \mathrm{~m}$ and $27 \mathrm{~m}$ cases are shown below for the rope length.

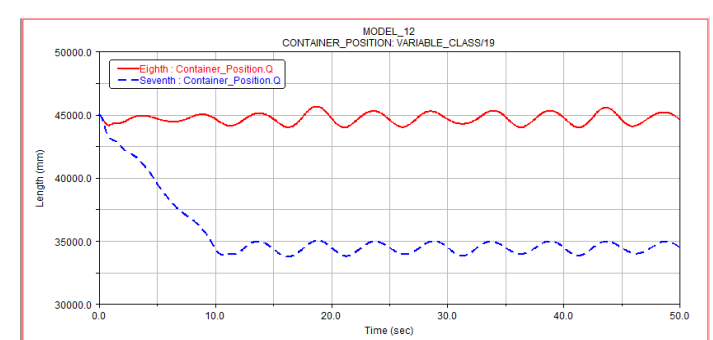

(a) vertical position of payload $(\mathrm{mm})$

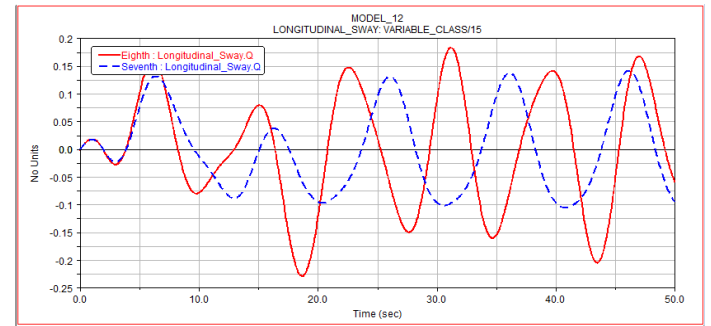

(b) the sway angle of payload ( $\mathrm{rad}$ )

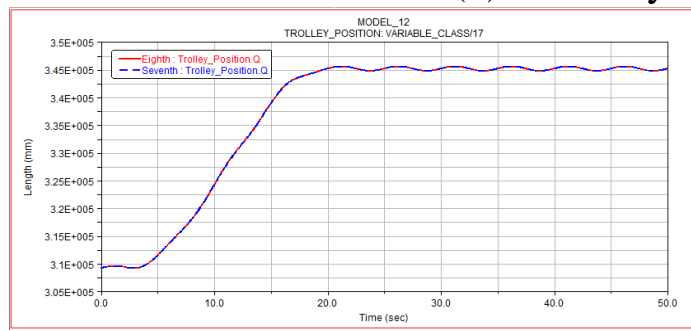

(c) the trolley position at $15 \mathrm{~m}$ and $27 \mathrm{~m}$ rope length $(\mathrm{mm})$

Figure 7. the simulation results with different rope length

It can be seen from the chart, $27 \mathrm{~m}$ wire rope was significantly higher than the $15 \mathrm{~m}$ wire rope hoists swing angles smaller, without affecting the positioning of the trolley.

\section{Summary}

It can be concluded as follow:

1). If only considered the position of the trolley and the sway angle of the swaying load, the planar model which has already neglected the pitching and surging of the ship can satisfy the simulation requirement.

2). Sea conditions make enormous influence on the payload's pivot and the trolley, therefore, the motion of the ship is considered as a big disturbance in this paper. 
3). When the wave excited frequency is close to the inherent frequency of the payload, a pivot angle will appear. So, in order to decrease the swing, the inherent frequency should be used to be away from the wave excited frequency.

4). The sway angle of the offshore container crane system is relevant to the length of the steel rope.

\section{References}

[1] Ismail, R. M. T. R. That, N. D., Ha, Q. P. Modelling and robust trajectory following for offshore container crane systems. Automation in Construction 59(2015), 179.

[2] Jonghoe, K. and James, R. M. Offshore Port Service Concepts: Classification and Economic Feasibility, Flexible Services and Manufacturing Journal 24(2012), 214.

[3] K.S. Hong, Q.H. Ngo. Dynamics of the Container Crane on a Mobile Harbor, Ocean Engineering, 53 (2012), 16.

[4] Baird, A. J. and Rother, D. Technical and Economic Evaluation of the Floating Container Storage and Transhipment Terminal (Fcstt), Transportation Research Part C-Emerging Technologies 30(2013), 178 .

[5] Y.G. Sun, H.Y. Qiang, X.M. Sheng. Genetic Algorithm-based parameters optimization for the PID Controller applied in Heave Compensation System. International Conference on Mechatronics Engineering and Computing Technology (Shanghai, CHINA, APR 09-10, 2014). Vol. 556-562, p. 2462.

[6] Y.G. Sun, H.Y. Qiang, G.B. Lin, J.D. Ren, W.L. Li. Dynamic Modeling and Control of Nonlinear Electromagnetic Suspension Systems[C]. International Conference on Applied Engineering and Management (Beijing, PEOPLES R CHINA, SEP 11-14, 2015). Vol. 46, p. 1039.

[7] Ngo, Q. H., Hong, K. S. (2012). Sliding-Mode Antisway Control of an Offshore Container Crane. IEEE-ASME Transactions on Mechatronics 17(2), 201-209.

[8] Y.G. Sun, H.Y. Qiang, D.F. CHANG, R. WANG. Response Characteristic Analysis of Nonlinear Vortex-Induced Vibration of Tension Leg Platform in Deep Sea [J]. Journal of the balkan tribological association, Vol.22 (2016) No.3, p.2519.

[9] Y. G. Sun, W.L. Li, D. S. Dong, X. Mei and H. Y. Qiang, Dynamics Analysis and Active Control of a Floating Crane [J], Tehnicki Vjesnik-Technical Gazette, Vol. 22 (2015) No.6, p.1383

[10] Dong, D. S., Sun, Y. G., Liu, L., Qiang, H. Y. Simulation Study on Dynamic Characters of Floating Crane Based on Virtual Prototype Technology. Mechanical Science and Technology for Aerospace Engineering Vol.34 (2015) No. 3, 393. (In Chinese) 